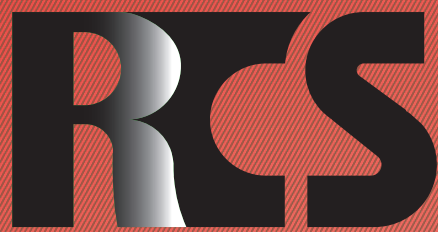

Depósito legal ppi $201502 Z U 4662$

Esta publicación científica en formato digital es continuidad de la revista impresa Depósito Legal: pp $197402 Z$ U789

- ISSN: 1315-9518 • ISSN-E: 2477-9431

Revista de Ciencias Sociales

Universidad del Zulia. Revista de la Facultad de Ciencias Económicas y Sociales Vol. XXVII,

No. 4,2021

Revista d

Sociales

Esta publicación científica en formato digital es continuidad de la revista impresa Depósito Legal: pp $197402 Z 1789$ ISSN: 1315-9518 


\title{
Procesamiento cerebral del lenguaje desde la perspectiva de la neurociencia y la psicolingüística
}

\author{
Arellano, Florcita Janeth* \\ Moreno del Pozo, Guido Francisco** \\ Culqui, César Oswaldo*** \\ Tamayo Arellano, Vicente Rodrigo ${ }^{* * * *}$
}

\section{Resumen}

El estudio busca identificar cómo el cerebro procesa el lenguaje desde la perspectiva de la Neurociencia y la Psicolingüística. El abordaje se hizo desde un paradigma cualitativo y el diseño de investigación fue de teoría fundamentada, para comprender este proceso en el cerebro y la relación entre conceptos que discuten la Neurociencia y la Psicolingüística, con alcance descriptivo-analítico analizando cuatro investigaciones de alto impacto. Los resultados resaltaron las imágenes del cerebro que fueron tomadas en dichas investigaciones por medio de una resonancia magnética funcional, en las que identifica la activación de zonas cerebrales que intervienen en las tareas del lenguaje asignadas. También, se identifica cómo los hemisferios actúan en el desarrollo del lenguaje, para conocer las funciones que estos desempeñan. Finalmente, se concluye que el área de Broca está centrada en el sistema gramatical y el área de Wernicke se centra en un sistema léxico y semántico desde el punto de vista de la Neurociencia, mientras que, desde la Psicolingüística, se identifica que el hemisferio izquierdo tiene la capacidad de discriminar las características importantes para segmentar las partes significativas. Además, el hemisferio derecho se centra en la percepción de los diferentes estímulos auditivos y visuales para la producción del lenguaje.

Palabras clave: Neurociencia; psicolingüística; área Broca; área Wernicke; lenguaje.

* Doctora en Gerencia Educativa. Magíster en Gerencia Educativa. Diplomado en Planificación y Gestión Educativa. Licenciada en Castellano y Literatura. Perito en Inglés. Delegada del Vicerrectorado Académico - Investigación en la Universidad Estatal de Bolívar, Ecuador. E-mail: farellano@ueb. edu.ec (iD) ORCID: https://orcid.org/0000-0002-4325-9317

** Doctor en Ciencias Pedagógicas. Magister en Gerencia Empresarial. Licenciado en Ciencias de la Educación. Especialización Educación Física Deportes y Recreación. Docente en la Universidad Estatal de Bolívar, Ecuador E-mail: fmoreno@ueb.edu.ec (iD) ORCID: https://orcid.org/0000-00025905-3145

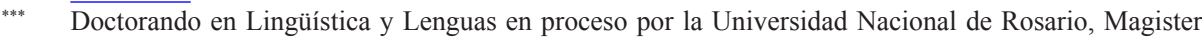
en Educación. Licenciado en Educación mención Inglés. Docente del Departamento de Idiomas en la Universidad Estatal de Bolívar, Ecuador. E-mail: cculqui@ueb.edu.ec (ID) ORCID: https://orcid. org/0000-0003-2564-1894

Máster en Comunicación con Fines Sociales. Licenciado en Relaciones Públicas y Comunicación Organizacional. Consultor en Identidad e Imagen Corporativa. E-mail: viche.tamayo@hotmail.com (iD) ORCID: https://orcid.org/0000-0002-8057-2812

Recibido: 2021-06-01 · Aceptado: 2021-08-18 


\title{
Brain language processing from the perspective of neuroscience and psycholinguistics
}

\begin{abstract}
The study seeks to identify how the brain processes language from the perspective of Neuroscience and Psycholinguistics. The approach was made from a qualitative paradigm and the research design was based on theory, to understand this process in the brain and the relationship between concepts discussed by Neuroscience and Psycholinguistics, with a descriptive-analytical scope analyzing four high-impact investigations. The results highlighted the images of the brain that were taken in these investigations by means of a functional magnetic resonance imaging, in which it identifies the activation of brain areas that intervene in the assigned language tasks. Also, it identifies how the hemispheres act in the development of language, to know the functions they perform. Finally, it is concluded that Broca's area is centered on the grammatical system and Wernicke's area is centered on a lexical and semantic system from the point of view of Neuroscience, while, from Psycholinguistics, it is identified that the left hemisphere it has the ability to discriminate the important characteristics to segment the significant parts. In addition, the right hemisphere focuses on the perception of different auditory and visual stimuli for the production of language.
\end{abstract}

Keywords: Neuroscience; psycholinguistics; Broca area; Wernicke area; language.

\section{Introducción}

El presente estudio se centra en realizar una descripción general de cómo la estructura del lenguaje influye en la forma en que se piensa y en las áreas del cerebro que ejercen función en el proceso del lenguaje. Se inicia con una revisión bibliográfica de términos como lengua, lenguaje y lingüística, haciendo énfasis en el lenguaje. También, se realizó una revisión sistemática de investigaciones realizadas en el área del lenguaje desde una visión clínica, el cual permitirá identificar áreas que se activan en el momento en que se realiza una tarea.

Los científicos enfocados en el lenguaje también estudian cómo se procesa en tiempo real, mediante el campo llamado Psicolingüística, que es un área del saber interdisciplinar entre la Lingüística y la Psicología; su principal objeto de estudio es la relación que se establece entre el saber lingüístico y los procesos mentales implicados
(Marín, 2007). La Psicolingüística, es una ciencia encargada del estudio de cómo los hablantes adquieren, entienden y en algunos casos pierden el lenguaje. La importancia de este enfoque es debido a que un estudio del lenguaje no puede realizarse sin tener en cuenta las disciplinas que aportan con diferentes puntos de vista como son la Neurología, Biología, y Psicología (Fernández, 2007; Hernández, Fernández y Baptista, 2014).

Se realizó una búsqueda de diversos estudios basados en metaanálisis, en los cuales se aplicaron diferentes técnicas estadísticas para analizar de forma cuantitativa los resultados alcanzados en los campos más utilizados del área clínica, enfocando esta investigación en la Neurociencia (Turkeltaub et al., 2002). Para ello, se explicaron las tecnologías que ayudan a observar y analizar el cerebro cuando se le asignan tareas referentes a la lengua, siendo la más importante la resonancia magnética.

Por medio de una resonancia magnética, se determinaron las áreas involucradas 
en el proceso del lenguaje, en la que se identifica, por medio de diferentes mapas, la activación cerebral (Geyer et al., 2011). Este punto es considerado importante, puesto que el presente estudio tiene como objetivo entender e interpretar cómo se activan las áreas del cerebro, y por este medio, conocer los procesos neurocognitivos que involucran los paradigmas. Desde el punto de vista de la Neurociencia, se investigó las áreas de activación cerebral que están involucradas en el proceso del lenguaje por medio de paradigmas en la asignación de tareas, punto que se ampliará en los resultados.

\section{Procesamiento del lenguaje}

El lenguaje ha evolucionado y se ha considerado como "maravilla del mundo natural" (Ardila, Bernal y Rosselli, 2014a). La comprensión de las funciones de las diferentes áreas del cerebro ha representado un importante esfuerzo para la Neurociencia. Históricamente, las funciones cerebrales se han asociado con áreas específicas del cerebro cortical; sin embargo, los desarrollos modernos de neuroimagen sugieren que las funciones cognitivas estén más asociadas a las redes. Las áreas Brodmann, dieron un fuerte apoyo a este modelo en 1909, describiendo 52 pares de áreas corticales del cerebro caracterizadas por una diferente organización laminar.

A pesar del subsiguiente desarrollo de mapas corticales, detallados como el mapa publicado por Economo y Koskinas en el año 2007 llamado "Brodmann áreas" (BA), se ha utilizado ampliamente en la neuroanatomía actual, proporcionando un sustrato topográfico a funciones específicas del cerebro. Los modelos tradicionales de lenguaje lo consideran en términos de áreas específicas del cerebro (como las de Broca y área de Wernicke) dedicada a funciones específicas (por ejemplo, idioma producción y comprensión del lenguaje). La Neurociencia contemporánea, sin embargo, enfatiza la idea de los sistemas cerebrales, incluyendo las áreas lingüísticas tradicionales, así como otras áreas que no pueden estar asociadas, sino que son involucradas en el procesamiento del lenguaje, lo cual se sintetiza en la Figura I.

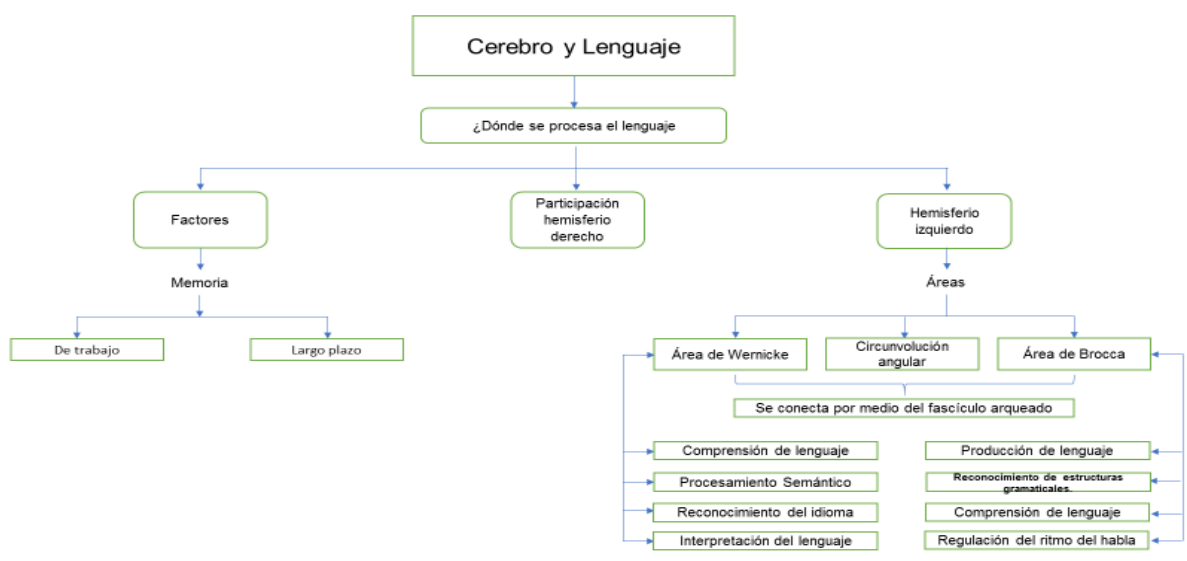

Fuente: Elaboración propia, 2021, adaptado de Cristiano (2016).

Figura I: Proceso del lenguaje 
Por otra parte, los mecanismos cognitivos y cerebrales ayudan a comprender el proceso lingüístico, desde el punto de vista de la Psicolingüística. La comprensión de la producción lingüística consiste en un acto carente de fases intermedias, debido a que los pasos que conducen son de una velocidad elevada que resulta imposible percibir. En la secuencia del proceso, de la misma manera en el sistema de comprensión oracional, se puede llegar a cometer errores debido a que se recibe y analiza información al mismo tiempo (Fernández, 2007).

Se pudo analizar y detallar, desde el punto de vista Psicolingüístico, que el lenguaje surgió desde el conjunto de aspectos biológicos, como puede ser la posición de la laringe, y aspectos sociales, como la cohesión y aspectos familiares (Fernández, 2007). Al respecto, sostienen Terranova et al. (2019) que: "De allí, se conoce que los procesos cognitivos y las estructuras neurocognitivas emergen y se desarrollan a través de múltiples interacciones, principalmente a partir de los factores del ambiente y del contexto, junto con elementos genéticos" (p.332).

Sepúlveda y Gaintza (2013), en el Cuadro 1, resumen las etapas del desarrollo del lenguaje desde la perspectiva Psicolingüística en período, edad y características. En el periodo Prelingüístico, de 0 a 12 meses, se desarrollan y estabilizan sonidos primarios, y llega a determinar el lenguaje como la primera aparición de la sensación muscular del aparato fonador con conexión a la sensación auditiva para la emisión del eco de la voz.

\section{Cuadro 1 \\ Etapas del desarrollo del lenguaje}

\begin{tabular}{|c|c|c|}
\hline Periodo & Edad & Características \\
\hline Prelingüístico & 0 a 12 meses & $\begin{array}{l}\text { En este periodo se desarrollan y estabilizan sonidos primarios, y } \\
\text { llega a determinar el lenguaje es la primera aparición de la sensación } \\
\text { muscular del aparato fonador con conexión a la sensación auditiva para } \\
\text { la emisión del eco de la voz. }\end{array}$ \\
\hline Lingüística & 1 a 6 años & $\begin{array}{l}\text { Comienza la evolución del lenguaje desde la pronunciación de las } \\
\text { primeras palabras, puesto que el niño busca comunicar sus ideas, la } \\
\text { cual es conocida como edad de locomoción- acción. En esta etapa no } \\
\text { experimenta avances en expresión, pero si en comprensión. } \\
\text { En este periodo también se encuentra la edad de titubeo posterior } \\
\text { a la edad de locomoción-acción, por la cual menciona más palabras } \\
\text { en relación a la evolución de su lógica y en función a las conductas } \\
\text { (ensayo-error). }\end{array}$ \\
\hline $\begin{array}{l}\text { Estructuración } \\
\text { del lenguaje }\end{array}$ & 2 a 7 años & $\begin{array}{l}\text { En este periodo alcanza en su totalidad el dominio del lenguaje en } \\
\text { la comunicación social y en el aprendizaje escolar; este periodo se } \\
\text { subdivide en edad de imitación, edad preescolar y la integración de la } \\
\text { articulación. }\end{array}$ \\
\hline $\begin{array}{l}\text { Abstracción e } \\
\text { introspección }\end{array}$ & 13 años en adelante & $\begin{array}{l}\text { En este periodo el desarrollo lingüístico dependerá del intelecto de cada } \\
\text { persona, del ambiente social y de su nivel cultural. }\end{array}$ \\
\hline
\end{tabular}

Fuente: Sepúlveda y Gaintza (2013).

En segundo lugar, en el periodo llamado lingüística de 1 a 6 años, comienza la evolución del lenguaje desde la pronunciación de las primeras palabras, puesto que el niño busca comunicar sus ideas, la cual es conocida como edad de locomoción- acción, y en esta etapa no experimenta avances en expresión, pero si en comprensión (ver Cuadro 1). En este periodo, también se encuentra la edad de titubeo, posterior a la edad de locomoción-acción, por 
la cual menciona más palabras en relación con la evolución de su lógica y en función a las conductas (ensayo-error).

Luego de esto, viene el periodo llamado estructuración del lenguaje de 2 a 7 años. En este periodo, alcanza en su totalidad el dominio del lenguaje en la comunicación social y en el aprendizaje escolar; este periodo se subdivide en edad de imitación, edad preescolar, y la integración de la articulación. Finalmente, en el periodo llamado abstracción e introspección que va desde los 13 años en adelante, el desarrollo lingüístico dependerá del intelecto de cada persona, del ambiente social y de su nivel cultural (ver Cuadro 1).

En este sentido, el lenguaje es una función cerebral altamente compleja, desde el punto de vista Psicolingüístico, se da por la interacción entre el medio social y desarrollo biológico del cerebro. El cerebro está divido en dos hemisferios, pero funcionan de diferente manera, en lo que involucra al proceso de lenguaje. El hemisferio derecho, está encargado de la producción de palabras y codificación de las mismas; el hemisferio izquierdo, se encarga del reconocimiento de la voz de los interlocutores, debido a que la corteza derecha no esta tan desarrollada como la izquierda, y el lenguaje necesita procesos más sofisticados y ordenados (Sepúlveda y Gaintza, 2013).

Desde la teoría psicolingüística, el proceso y desarrollo del lenguaje, abarca en su conjunto procesos de comprensión como son los de producción; y por otra parte, la dimensión escrita y oral (Coelho, 2017). Basándose en el modelo Levet para establecer un sistema sintáctico, retorico y semántico, los cuales actúan en la formulación conceptual, dicha formulación organiza un mensaje pre verbal, por lo cual, gramaticalmente es codificado por medio del lexicón mental. Con la codificación gramatical, se llega a la actuación de los sistemas fonético y fonológico, así como a la estructura superficial; por medio de estas se produce la codificación morfológica, de la cual surge la codificación fonética que da lugar a la articulación que se realiza en la situación del habla (Yepes, 2013).
La unión del sistema lingüísticocognitivo, se organiza al nivel de la palabra, en el que se encuentran los elementos de conversación de lo ortográfico en grafémica o de lo auditivo a lo fonológico. Los niveles inferiores de la palabra de conversación conducen a las salidas grafémicas y fonológicas, los cuales organizan a la conversación de lo ortográfico en lo fonológico en la preparación del habla. Existen dos aspectos importantes, la primera, los niveles de codificación y decodificación desde la concepción de la Psicolingüística, es decir, que unifica el sistema cognitivo lingüístico; y el segundo aspecto, facilita una conversación de lo ortográfico a lo fonológico (Paredes y Varo, 2006).

En tal sentido, la resonancia magnética es una de las tecnologías imprescindibles que la Neurociencia moderna utiliza como instrumento de cartografía cerebral. Las técnicas de imagen funcional, especialmente la imagen de resonancia magnética funcional (IRMf), mapean el córtex con una resolución espacial cada vez mayor, pero lo tienen activado y correlacionado solo con macroanatomía (giros y surcos). La electrofisiología invasiva en animales experimentales (por ejemplo, macacos), sin embargo, muestra bordes funcionales donde la microanatomía cambia (Luppino et al., 1991).

Desafortunadamente, la microanatomía es variable topográficamente a través del cerebro y es difícil de detectar con resonancia magnética. Por lo tanto, las correlaciones estructural-funcionales, basadas únicamente en la macroanatomía, son cuestionables y puede explicar al menos algunos de los resultados contradictorios que los estudios de imágenes funcionales han proporcionado en el pasado.

El Atlas de Talairach - Tournoux (1988 y 1993), también tiene un valor limitado (Nowinski y Belov, 2003). Los autores adoptaron la nomenclatura de áreas de Brodmann, pero sus mapas corticales no se basan en datos microestructurales. Además, el Atlas indica solo la posición aproximada de cada área (los bordes entre las áreas no 
están marcados), e ignora el problema de la variabilidad interindividual (solo se representa un cerebro). Como se muestra en la Figura
II, el Atlas de Talairach- Tournoux utiliza las áreas de Brodmann como etiquetas para las regiones del cerebro. a)

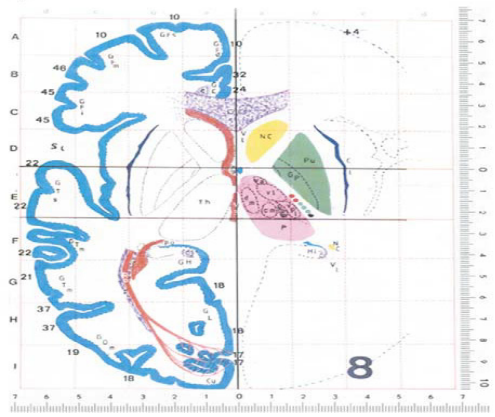

b)

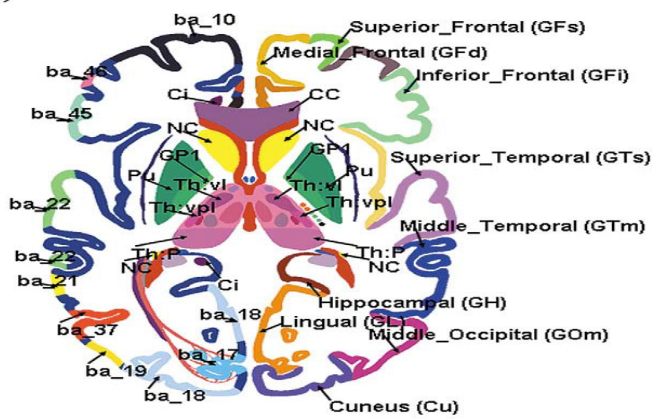

Fuente: Nowinski y Belov (2003).

Figura II: Atlas cerebral electrónico de Talairach - Tournoux

En este punto, en el atlas cerebral electrónico de Talairach-Tournoux se muestra: (a) Placa axial digitalizada original; (b) la imagen electrónica correspondiente del Atlas totalmente codificada por color y etiquetada con estructuras subcorticales, giros y áreas de Brodmann. Varias estructuras subcorticales no están disponibles en el Atlas de impresión (por ejemplo, el talámico izquierdo subnúcleos o el ventrículo lateral derecho), se incluyen en el Atlas electrónico (Nowinski y Belov, 2003).

Existen diferentes mapas de activación cerebral según Geyer et al. (2011). En primer lugar, técnicas de mapeo microestructural más sensibles, desarrolladas desde la época de Brodmann, por ejemplo, la proteína de neurofilamento. En segundo lugar, el libro de Brodmann, en contraste con Triarhou no proporciona descripciones verbales o pictóricas de las características citoarquitectónicas de cada área. En muchos casos, solo comenta brevemente sus ubicaciones topográficas. El mapa muestra la ubicación de cada área y solo en la superficie cortical expuesta, los surcos no se abren, y no hay información disponible sobre la topografía de cada área dentro de cada surco.

Por lo tanto, es muy difícil comparar el mapa de Brodmann con los de otros autores, y virtualmente es imposible volver a mapear sus áreas en secciones histológicas teñidas para cuerpos celulares. En tercer lugar, los mapas cerebrales "clásicos", como la parcelación de Brodmann, se publicaron en formato de impresión bidimensional. Esto plantea problemas cuando los datos estructurales de estos mapas deben combinarse con datos de otros cerebros. Los mapas "clásicos", son dibujos esquemáticos que reflejan la situación topográfica en un cerebro y no abordan el problema de la variabilidad interindividual. Además, estos mapas son "rígidos", es decir, no están basados en un sistema de referencia espacial y no puede ser deformado a otros cerebros.

La integración multimodal de datos estructurales y funcionales es imposible. Aunque los programas de software, que son 
capaces de inflar y/o aplanar la corteza están disponibles en la actualidad, por ejemplo, FreeSurfer1, Caret2, o BrainVoyager3, se siguen presentando los problemas anteriores con el mapa de Brodmann. Para interpretar o entender cómo se activan las áreas del cerebro, se debe tener conocimiento de procesos neurocognitivos que involucra paradigmas. Primero, es necesario considerar las diferencias individuales: Conocer cómo se presentan los diferentes acontecimientos o actividades que afectan el acoplamiento neurovascular, y que generan diferencias entre los individuos en el estado de oxigenación.
Segundo, durante el reposo en los paradigmas se pueden activar una serie de regiones en las áreas de Brodmann. Tercero, se debe considerar el hecho que, aunque un área se active no es indispensable para esa tarea en cuestión. Cuarto, inversamente el hecho que no se activen ciertas áreas esperadas durante la ejecución de una tarea, no indica presumir que no participan en el proceso, es posible que participen, pero puede ser que la resonancia magnética que captura la actividad cerebral no haya alcanzado a captarlo (véase el Cuadro 2).

\section{Cuadro 2}

\section{Estudios primarios de paradigmas relacionados con el lenguaje incluidos en el} metaanálisis (26 estudios; 39 paradigmas; 522 sujetos)

\begin{tabular}{|c|c|c|c|}
\hline Publicación & Paradigma & No & Focos \\
\hline \multirow[t]{2}{*}{ Booth et al., 2002} & Monitor semántico / discriminación & 13 & 15 \\
\hline & Discriminación fonológica & 13 & 7 \\
\hline Simon et al., 2002 & Discriminación fonológica & 10 & 7 \\
\hline Michael et al., 2001 & Monitor semántico / discriminación & 9 & 18 \\
\hline \multirow{3}{*}{$\begin{array}{l}\text { Palmer et al., } 2001 \\
\text { Shaywitz et al., } 1995\end{array}$} & Completar palabra raíz & 10 & 26 \\
\hline & Generación de palabras & 9 & 15 \\
\hline & Generación de palabras & 9 & 11 \\
\hline Dapret to y Bookheimer, 1999 & Monitor semántico / discriminación & 8 & 8 \\
\hline Schlosser et al., 1998 & Generación de palabras & 6 & 11 \\
\hline Binder et al., 2003 & Monitor semántico / discriminación & 24 & 9 \\
\hline \multirow[t]{2}{*}{ Poldrack et al., 2001} & Monitor semántico / discriminación & 8 & 5 \\
\hline & Monitor semántico / discriminación & 8 & 5 \\
\hline Riecker et al., 2000 & Recitación / repetición & 18 & 6 \\
\hline Rowan et al., 2004 & Generación de palabras & 10 & 13 \\
\hline Pihlajamaki et al., 2000 & Generación de palabras & 14 & 9 \\
\hline Gurd et al., 2002 & Generación de palabras & 11 & 8 \\
\hline Kemeny et al., 2005 & Generación de palabras & 6 & 12 \\
\hline Voets et al., 2006 & Generación de palabras & 12 & 14 \\
\hline \multirow[t]{2}{*}{ Bohland y Guenther, 2006} & Recitación / repetición & 13 & 18 \\
\hline & Recitación / repetición & 13 & 54 \\
\hline Seghier et al., 2008 & Monitor semántico / discriminación & 50 & 10 \\
\hline \multirow[t]{3}{*}{ Thompson et al., 2007} & Monitor semántico / discriminación & 17 & 25 \\
\hline & Monitor semántico / discriminación & 17 & 28 \\
\hline & Monitor semántico / discriminación & 17 & 31 \\
\hline \multirow[t]{2}{*}{ Haller et al., 2005} & Generación de palabras & 15 & 9 \\
\hline & Generación de palabras & 15 & 7 \\
\hline \multirow[t]{2}{*}{ Damasio et al., 2001} & Nombrar & 20 & 5 \\
\hline & Nombrar & 20 & 4 \\
\hline Simmons et al., 2008 & Generación de palabras & 10 & 32 \\
\hline
\end{tabular}




\section{Cont... Cuadro 2}

\begin{tabular}{llcc}
\hline & Generación de palabras & 10 & 23 \\
Sharp et al., 2010 & Monitor semántico / discriminación & 12 & 13 \\
Davis, Meunier y Marslen-Wilson, & Sustantivo complejo vs. sustantivo simple & 12 & 2 \\
2008 & Monitor semántico / discriminación & 12 & 14 \\
Longe et al., 2007 & Monitor semántico / discriminación & 12 & 13 \\
& Monitor semántico / discriminación & 12 & 4 \\
& Monitor semántico / discriminación & 12 & 2 \\
Berlingeri et al., 2008 & Nombrar & 12 & 14 \\
Tyler et al., 2005 & Discriminación fonológica & 18 & 9 \\
& Discriminación fonológica & 18 & 7 \\
\hline
\end{tabular}

Fuente: Ardila et al. (2014a).

Como ejemplo de lo dicho anteriormente, se menciona un estudio elaborado por Ardila et al. (2014a), éste utiliza materiales y métodos que ayudan a sustentar su investigación y se detalla de la siguiente manera: A la base de datos de Brainmap se accedió utilizando Sleuth 2.2 el 10 de octubre de 2013, por lo mismo, Sleuth es un software provisto por BrainMap para consultar datos. El objetivo del metaanálisis fue evaluar la red de coactivaciones en las que está involucrada la ínsula. Las condiciones de búsqueda fueron: (1) Estudios que informaron la activación de la ínsula; (2) estudios utilizando fMRI; (3) contexto: Sujetos normales; (4) activaciones: Solo activación; (5) manos: Sujetos diestros; (6) de 20 a 60 años; (7) dominio: Cognición, subtipo: Lenguaje.

Ardila, Bernal y Rosselli (2014b), demuestran los principales focos de conectividad cerebral de la ínsula, en cuyo estudio encontraron trece grupos diferentes de activación, en su mayoría relacionados con el hemisferio izquierdo.

\section{Metodología}

El abordaje o la construcción del diseño de investigación fue de teoría fundamentada, dado que se utiliza para preguntas sobre procesos y relación entre conceptos (EstradaAcuña, Arzuaga y Giraldo, 2019); en este caso, para entender, cómo el cerebro procesa el lenguaje, desde la Neurociencia y la Psicolingüística, se indagaron documentos de alto impacto que sirvieron como instrumentos, los cuales se usaron de una forma no pasiva para estudiarlos y analizarlos en cualquier momento (ver Cuadro 3). Incluso, para analizar las áreas que se activan en el cerebro cuando la persona empieza a activar el lenguaje. 


\section{Cuadro 3}

\section{Documentos de alto impacto}

\begin{tabular}{lll}
\hline Artículo & Revista & Enfoque \\
\hline $\begin{array}{l}\text { Participation of the insula in language } \\
\text { revisited: A meta-analytic connectivity } \\
\text { study (Ardila et al., 2014a). }\end{array}$ & $\begin{array}{l}\text { Journal of } \\
\text { Neurolinguistics }\end{array}$ & $\begin{array}{l}\text { Se realiza una revisión sistemática, en el cual se } \\
\text { identifica el papel de la ínsula en el lenguaje con } \\
\text { una evaluación meta analítica, para identificar la } \\
\text { probabilidad de activación. }\end{array}$ \\
$\begin{array}{l}\text { Neuropsicología y la localización de } \\
\text { las funciones cerebrales superiores } \\
\text { en estudios de resonancia magnética } \\
\text { funcional con tareas (Cabrales, 2015). }\end{array}$ & $\begin{array}{l}\text { Acta Neurológica } \\
\text { Colombia }\end{array}$ & $\begin{array}{l}\text { Se analizaron diversos conceptos sobre resonancia } \\
\text { magnética funcional, de las cuales se identificó } \\
\text { las funciones cerebrales superiores y las áreas } \\
\text { cerebrales activadas en relación a paradigmas. }\end{array}$ \\
$\begin{array}{l}\text { Una aproximación a la lectura: La } \\
\text { perspectiva psicolingüística (Yepes, }\end{array}$ & $\begin{array}{l}\text { Universidad de } \\
\text { 2013). }\end{array}$ & $\begin{array}{l}\text { Se identifica las etapas del desarrollo del lenguaje } \\
\text { por edad en el crecimiento de las personas con un } \\
\text { enfoque psicolingüístico. }\end{array}$ \\
$\begin{array}{l}\text { Perspectivas inherentes al desarrollo } \\
\text { del Lenguaje. Aportaciones desde la } \\
\text { psicolingǘstica (Sepúlveda y Gaintza, } \\
\text { 2013). }\end{array}$ & Revista & $\begin{array}{l}\text { Se identificó el desarrollo del lenguaje enfocado y } \\
\text { el proceso del mismo bajo perspectivas inherentes } \\
\text { por medio de la aportación psicolingüística. }\end{array}$ \\
\hline
\end{tabular}

Fuente: Elaboración propia, 2020.

Estos documentos se convirtieron en un material narrativo muy valioso, por ende, utilizando el paradigma cualitativo con alcance descriptivo, se diseñó estratégicamente la metodología. Se realizó una revisión que consistió en un proceso de búsqueda y localización de información disponible, así como publicada en relación a lo planteado, identificando como criterio de selección, investigaciones que hayan cumplido con un proceso cuantitativo (metaanálisis), el cual es una parte de la revisión sistemática. Dicho proceso combina los resultados individuales para esquematizarlos y dar una descripción más acertada.

En los resultados, se presenta información que fue analizada por medio de imágenes de resonancia magnética funcional en relación con la evaluación de tareas del lenguaje y la activación de zonas cerebrales en cumplimiento con las tareas del lenguaje asignadas. Se procesaron, desde el área de la Neurociencia, los grupos de activación del lado izquierdo del cerebro donde se genera el proceso del lenguaje.

\section{Resultados y discusión}

La ínsula se encuentra en el epicentro del área del lenguaje, pero su papel específico no se comprende en su totalidad, por lo que se realizó un metaanálisis con la aplicación de la técnica de estimación de la probabilidad de activación, donde se identificaron áreas involucradas en la repetición del lenguaje y otras funciones lingüísticas. Se encontraron 13 grupos de activación diferentes y por este motivo se determinó que la ínsula es un área central en el procesamiento del lenguaje.

A continuación, en la Figura III, se presentan el foco principal del cerebro y su conectividad con la ínsula a través de la información, 13 diferentes grupos de activación se encontraron, en su mayoría relacionados con el hemisferio izquierdo. Estos 13 grupos nacen de los resultados de los estudios primarios de paradigmas relacionados con el lenguaje incluidos en el metaanálisis (26 estudios; 39 paradigmas; 522 sujetos) (véase Cuadro 2). 


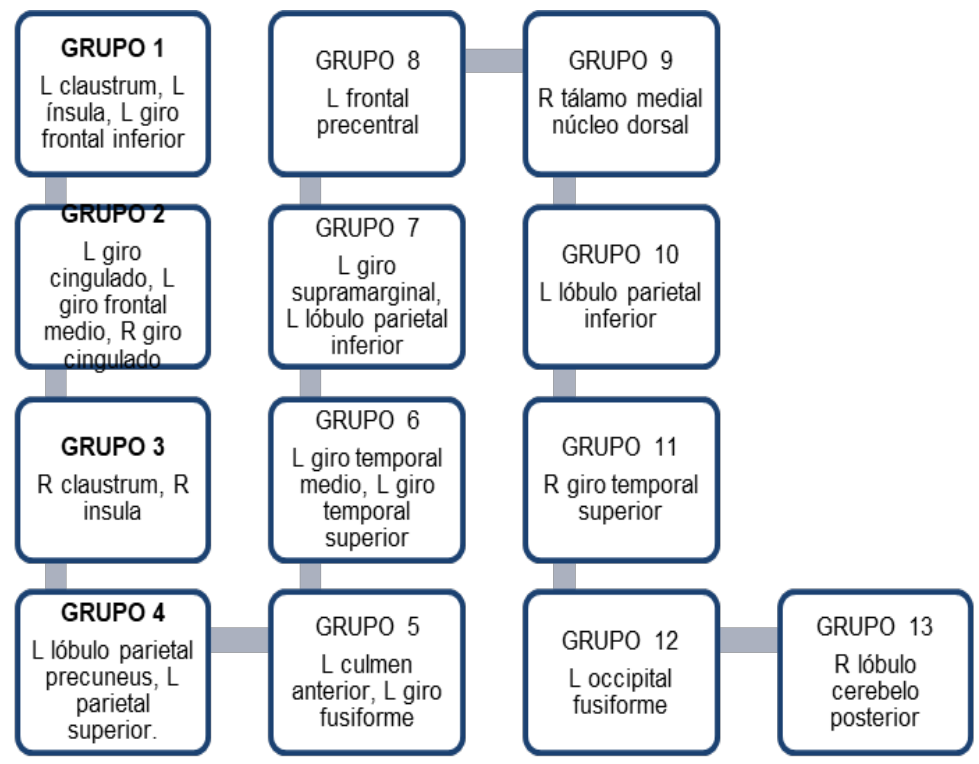

Fuente: Ardila et al. (2014a).

\section{Figura III: Principales loci de conectividad cerebral de la ínsula en tareas de lenguaje mediante el Modelo de Conectividad Meta-analítica (MACM)}

Los resultados de la estimación de la probabilidad de activación (ALE) se superpusieron en una plantilla de la imagen de resonancia magnética T1 (MRI). El hemisferio izquierdo (ver Figura IV) aparece en el lado izquierdo de la inserción (convención neurológica). Los principales focos de activación están situados en la ínsula izquierda BA9 (giro frontal medio); BA44 (área de Broca, pars opercularis); giro cingulado izquierdo SMA; ínsula derecha izquierda BA7 (lóbulo parietal superior); izquierda BA37 (giro fusiforme); izquierda BA22 (giro temporal medio superior); izquierda BA40 (giro supramarginal, lóbulo parietal inferior); BA4 giro precental izquierdo; dorsal medial núcleo del tálamo; BA40 (lóbulo parietal inferior); derecha BA41 (giro temporal superior, corteza auditiva primaria); BA19 (izquierda) giro occipital fusiforme; y lóbulo posterior derecho del cerebelo.

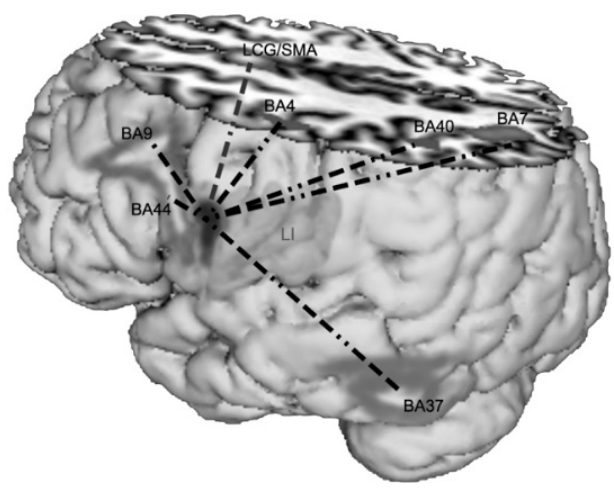

Fuente: Ardila, Bernal y Rosselli (2016).

Figura IV: Representación artística de las conexiones internas (hemisferio izquierdo)

El primer grupo incluye el claustrum 
(que es la materia gris subcortical insular); pero este enfoque se extiende no solo subcorticalmente, sino también anteriormente hacia el BA9 (giro frontal medio en la corteza prefrontal, involucrada en procesos complejos del lenguaje, incluyendo el uso de estrategias verbales en funciones ejecutivas).

Rosselli, Ardila y Bernal (2015), menciona que el segundo grupo incluye tanto la circunvolución cingulada anterior (involucrada en la organización motora-motor preparación / planificación, inhibición cognitiva / motora e iniciativa de lenguaje), como BA6 (giro frontal medio). BA6 incluye el área motora suplementaria (SMA), claramente involucrada en el inicio del lenguaje y mantenimiento de la producción voluntaria del habla. Por lo tanto, este segundo grupo sugiere una participación de la ínsula en un circuito cerebral que controla la iniciativa verbal y el mantenimiento de la producción del habla.

El grupo 3, incluye la ínsula derecha y la materia gris subcortical insular (claustrum) e indica una actividad integrada de ambos, la ínsula izquierda y derecha. El grupo 4, se refiere a la izquierda BA7 (lóbulo parietal superior); esta área del cerebro está involucrada en la praxis ideo motora, motor imágenes, aprendizaje motor, procesamiento de lenguaje, y reconocimiento de contexto temporal; Así, aparentemente, la ínsula también está involucrada en el lenguaje (Ardila, 2015).

El grupo 5, involucra el área BA37 (giro temporal inferior posterior, giro temporal medio, y giro fusiforme), y los cúlmenes cerebelosos; sin embargo, considerando que BA37 está exactamente por encima del culmen, lo más probable es que esta activación se refiera a BA37, por lo que el grupo 5 simplemente incluye el BA37 izquierdo. Es bien sabido que BA37 está involucrado en asociaciones léxico-semánticas (es decir, asociando palabras con elementos visuales y perceptos); observaciones clínicas han demostrado que el daño en el BA37 izquierdo está asociado con dificultades significativas para encontrar palabras, alteración del nombre de las imágenes, significante cantidad de parafasias semánticas y comprensión de palabras relativamente conservadas (Esteban, 2014).

Los siguientes dos grupos, es decir 6 y 7 , se refieren a dos áreas tradicionalmente involucradas en el lenguaje: izquierda BA22 (giro temporal superior: Parte de la zona de Hernicke), e izquierda BA40 (giro supramarginal). El primero, es considerado como un área crucial en la comprensión del lenguaje; mientras que la segunda, se ha relacionado con repetición del lenguaje y procesamiento semántico (Gutiérrez, 2014).

De igual manera, los siguientes grupos de activación 8 y 9, incluyen el BA4 izquierdo (corteza motora primaria - giro precentral) y el núcleo dorsal medial del tálamo, que recibe aportes del hipotálamo, así como proyectos a la corteza prefrontal y se ha relacionado con la atención y la memoria. Aunque directamente la relación con el lenguaje no es evidente, los grupos 8 y 9 pueden estar contribuyendo en aspectos del habla y el control de la atención del lenguaje. El grupo 10, por otra parte, es similar al agrupamiento 7 e incluye BA \# 40 (lóbulo parietal inferior) (Gutiérrez, 2014).

Los últimos tres grupos (particularmente más pequeños, con $300 \mathrm{~mm} 3$ o menos) incluyen el BA41 (primario) (corteza auditiva - giro de Heschl), BA19 (corteza visual secundaria - giro occipital inferior o fusiforme), y el lóbulo posterior del cerebelo, que de hecho podría ser una extensión del giro fusiforme activado. La activación de estos grupos puede sugerir alguna participación de la ínsula en el lenguaje, reconocimiento y asociaciones visuales (Ardila, 2015).

Es importante destacar la importancia de la resonancia magnética funcional con la asignación de tareas, con la finalidad de evaluar diversas funciones del cerebro por medio de la asignación y ejecución de paradigmas, las cuales producen la activación de diferentes zonas cerebrales. A continuación, en el Cuadro 4 se describe la función cerebral y el paradigma asignado a cada función, así como las áreas cerebrales que se activaron. 


\section{Cuadro 4 \\ Tareas cognitivas y la activación de áreas cerebrales}

\begin{tabular}{|c|c|}
\hline Función Cerebral & Paradigma \\
\hline \begin{tabular}{llr} 
Lenguaje & \multicolumn{2}{c}{ oral } \\
(estimulo visual & $\mathrm{y}$ \\
auditivo) & &
\end{tabular} & $\begin{array}{l}\text { Se pide a la persona que lea diversas frases, } \\
\text { y posteriormente seleccione la respuesta } \\
\text { correcta. Se puede hacer de forma verbal, } \\
\text { pero se considera la respuesta de la persona } \\
\text { generada de forma silenciosa, el control de este } \\
\text { paradigma se identifica diferentes símbolos no } \\
\text { lingüísticos }\end{array}$ \\
\hline $\begin{array}{l}\text { Lenguaje oral } \\
\text { (decisión semántica) } \\
\text { Estímulo visual }\end{array}$ & $\begin{array}{l}\text { Se presenta a la persona dos palabras } \\
\text { con relación semántica, una palabra debe } \\
\text { encontrarse en una categoría subordinada y } \\
\text { otras dos palabras sin encontrarse en la misma } \\
\text { categoría. La persona debe responde con un no } \\
\text { o con un sí, dependiendo si tiene relación o no } \\
\text { a la semántica. El control de este paradigma } \\
\text { es emparejar y elegir símbolos no lingüísticos } \\
\text { iguales. }\end{array}$ \\
\hline
\end{tabular}

Lenguaje

(Símbolos

Se ejecuta una narración de 10 segundos y no lingüísticos vs Lectura de texto)

y
después otra diferente, las cuales se debe leer y entender correctamente. El control es la presentación de varios símbolos no lingüísticos al igual que la narración.

Se presentan diferentes pares de palabras,

Lenguaje oral (rimas) palabras que rimen y otra que no lo hagan. La persona debe responder si riman o no.

Control: se presentan pares de símbolos iguales o no y debe responder si o no, si son iguales.

Lenguaje oral (Producción Se presenta a un individuo una letra, la persona debe pensar diferentes palabras que comiencen palabras en silencio) con letra mas no con palabras derivadas, el control de este paradigma se la realiza con símbolos no lingüísticos.

Lenguaje oral

(Denominación objetos simples)
Se presentan objetos simples de uso común. El control de este paradigma se presenta con símbolos no lingüísticos.

\section{Áreas cerebrales (Activas)}

Estimulo auditivo

Corteza auditiva primaria (Área de Heschl bilateral)

Estímulo es visual

Estructuras parietales (Giro frontal medio) Corteza temporal superior

Corteza frontal inferior

Unión del giro supramarginal del lóbulo parietal y el giro temporal superior posterior

Giro temporal medio e inferior izquierdo

Áreas suplementarias de movimientos oculares y áreas frontales de la mirada

Área izquierda de Broca

Corteza prefrontal dorsolateral inferior izquierda

En menor grado corteza visual primaria bilateral

Cuando hay respuesta

Áreas primarias y secundarias visuales ante símbolos no lingüísticos

Giro frontal medio.

Giro temporal superior posterior del hemisferio dominante para el lenguaje. Giro angular parietal (área de Wernicke)

Corteza prefrontal dorsolateral.

Giro frontal inferior

Giro temporal superior

Recubrimiento cortical del surco temporal superior

Giro fusiforme de la corteza temporooccipital ventral: área visual de las palabras

Áreas motoras suplementarias

Regiones motoras y premotoras

Corteza prefrontal dorsolateral

Cíngulo- área del lenguaje.

En menor grado corteza posterior del lenguaje (Wernicke) y corteza temporooccipital ventral

Giro frontal inferior

Giro temporal inferior

Giro frontal inferior/opérculo frontal

Área motora suplementaria

Corteza temporo-occipital ventral

Corteza prefrontal dorsolateral o corteza premotora

Corteza del lenguaje temporo parietal posterior 


\section{Cont... Cuadro 4}

Lenguaje oral (escucha pasiva)
Se lee para la persona una pequeña narración, el que debe. El control del paradigma es identificar si la narración se lo realizar al revés.
Lenguaje oral (comprensión lenguaje-estimulo visual)
Se presentan al sujeto dos frases, la segunda frase debe ser una pregunta relacionada con la primera frase y debe responder si las frases están o no relacionadas, el paradigma se controla por la presencia de símbolos no lingüístico.
Existen dos condiciones: a la persona se le presenta varias fotos de objetos y la persona tiene que memorizar los objetos, después deberá identificar dos objetos que ya memorizo. Las imágenes se deben colocar en ángulos donde se eviten los movimientos oculares. El control de esta fijación es el punto de fijación

Se escribe nombres de diversos colores, pero escrita en tinta de otro color al mencionado. Se Atención (Atención selectiva) le pide al sujeto que lo mencione en voz baja el color de la tinta en la cual está escrita la palabra y que inhiba la lectura.
Capa de la corteza del surco temporal superior en el área de Wernicke

Giro temporal superior

Surco temporal superior y giro temporal medio más anterior

En algunas personas se activa el giro frontal inferior

Giro frontal medio (memoria de trabajo). Área de Brocca izquierda en la corteza frontal inferior izquierda

Áreas hipocampales.

Área visual frontal

Áreas corteza prefrontal

Giro temporal posterior superior. Área de Wernicke.

Lóbulos occipitales: área visual suplementaria

Movimientos de los ojos: Surco precentral. Lóbulo frontal medial y surco intraparietal.

Lóbulos occipitales.

Hipocampo derecho.

Regiones corticales mesiotemporales y dorsolateral prefrontal.

Cíngulo anterior, área 32 de Brodmann del hemisferio derecho

Cíngulo central, áreas 31 y 23 de Brodmann del hemisferio izquierdo

Núcleo caudado: cuerpo derecho y cola izquierda

Tálamo bilateral

Fuente: Cabrales (2015).

El estudio de conectividad de una revisión sistemática actual, revela la participación de la ínsula izquierda en una compleja red cerebral involucrada en diferentes aspectos del lenguaje. Esta observación es congruente con el informe que la ínsula anterior participa en la planificación motora del habla (Valencia, 2015). Es bien sabido que la apraxia del habla (que es precisamente un defecto en la planificación motriz del habla) representa uno de los dos déficits fundamentales en la afasia de Broca (Blasco, 2006); el otro es el agramatismo, específicamente relacionado con el área de Broca y claramente conectado con la ínsula izquierda.

Por otra parte, representa un apoyo adicional para la observación que el daño de la ínsula puede asociarse con deficiencias en la capacidad de iniciar y mantener la producción voluntaria del habla y el mutismo (Bolaños, 2014; Flores y Yánez, 2015). Se ha establecido que el daño mesial frontal puede asociarse con el mutismo y, en casos graves, con el mutismo acinético. Además, la ínsula también parece estar involucrada en algunos aspectos contextuales y de aprendizaje motor del habla. 
La asociación de la ínsula con el área BA37 (giro temporal inferior posterior, giro temporal medio y el giro fusiforme), se refiere a un nivel diferente de lenguaje: denominación y comprensión del lenguaje. Esta suposición está respaldada por la observación que la ínsula también está conectada significativamente con el área de Wernicke (BA22; giro temporal superior).

La asociación con el BA40 izquierdo (giro supramarginal), sugiere que la ínsula puede estar involucrada en circuitos relacionados con la repetición del lenguaje, teniendo en cuenta que los defectos de repetición del lenguaje asociados con la afasia de conducción se observan en las lesiones del BA40 (Ardila et al., 2016). Es de destacar, que el daño de la ínsula puede provocar una afasia de conducción e históricamente, el primer caso de afasia de conducción se informó en un paciente con patología insular (Ardila, 2016).

Las correlaciones clínicas / anatómicas han sugerido que la ínsula puede estar involucrada en múltiples funciones de la guía, incluida la producción del lenguaje, la comprensión del lenguaje y la repetición del lenguaje. De hecho, la patología de la ínsula izquierda se ha relacionado con la afasia de Broca (por ejemplo, la apraxia del habla), la afasia de conducción (por ejemplo, defectos de repetición del lenguaje), y también la afasia de Wernicke (por ejemplo, deficiencias en la comprensión del lenguaje). Desafortunadamente, el interés en la posible implicación de la ínsula en el lenguaje desapareció durante casi un siglo.

Esta falta de interés en el papel potencial de la ínsula en el lenguaje puede estar relacionada con el concepto de "zona del lenguaje" en el cerebro (Vaca, 2013); esta zona de idioma (o área de idioma) incluye el frontal izquierdo (parte posterior del pie de F3, el opérculo frontal y la zona circundante inmediata, incluido el pie de F2, y probablemente se extiende hasta la ínsula anterior), y temporal (que abarca el primer y segundo giro temporal y las áreas parietales giro angular). El concepto de área del lenguaje, fue aceptado por la mayoría de los investigadores en el área y la ínsula fue descuidada durante la mayor parte del siglo XX. Las técnicas de neuroimaginación contemporáneas, sin embargo, apoyan la conclusión que se resiente un área central en el procesamiento del lenguaje, involucrada en una diversidad de funciones del lenguaje que incluyen tanto la comprensión como la producción, el aprendizaje léxico y gramatical, e incluso en la adquisición de un segundo idioma.

Los hallazgos encontrados anteriormente, permitieron identificar y comprender la teoría de la dominancia cerebral, esta teoría está respaldada en que las personas que controlan su mano derecha dominan el hemisferio izquierdo, lo que conlleva a pensar que el hemisferio derecho no mantenía gran relevancia en el pensamiento, determinando cómo es el procesamiento del lenguaje de los hemisferios (Gómez, 2004). Este tipo de conocimiento implica tener una visión más amplia para la Neurociencia desde el aprendizaje y la educación, debido a la comprensión de procesos educacionales.

Desde la Neurociencia, se busca explicar cómo actúan las células individuales nerviosas en el encéfalo para producir la conducta, y a la vez, dichas células están influidas por el ambiente en el que se rodea, por lo que desencadena el considerar la importancia de la Neurociencia y los resultados de la investigación en la educación, aportando a la revisión y construcción de conocimientos básicos. El cerebro tiene una funcionalidad global, por lo cual el lenguaje es una de las funciones que más se desarrollan, por esta razón en la complejidad de las funciones cerebrales se encuentran involucradas más áreas cerebrales (De la Barrera y Donolo, 2009).

\section{Conclusiones}

Las áreas específicas del cerebro son el área de Broca y el área de Wernicke que cumplen funciones específicas, en el cual, el área de Broca, está centrado en el sistema 
gramatical y su función principal es unir los diferentes elementos del lenguaje. Un ejemplo claro es la generación y extracción de significados, donde, de forma general, el área Broca mantiene un control cognitivo puesto que participa en la construcción de elementos para producción verbal. Por otra parte, el área de Wernicke está centrado en un sistema léxico y semántico del cual se comprueba la participación en los procesos verbales. Como un punto específico, esta área es conocida como el área de procesamiento auditivo del lenguaje.

Este punto de vista revela claramente la pregunta inicial de este estudio, ¿Cómo el cerebro procesa el lenguaje? y ¿Cómo el lenguaje posee muchas aplicaciones prácticas?, así como también que el conocimiento teórico y práctico (vivencial) se expresan por escrito y el área dependiente del complejo de Broca (producción del lenguaje y gramática). La importancia de saber que el lenguaje oral depende del cerebro, así como el desarrollo intelectual.

Como otro punto a destacar, se presenta la diferenciación del proceso del lenguaje en cada hemisferio. Por una parte, el hemisferio izquierdo, tiene un proceso secuencial, en el cual la percepción y generación verbal depende del conocimiento de la secuencia o el orden en el que se generan los diversos sonidos. Este proceso se centra en la capacidad de discriminar las características importantes para segmentar las partes significativas; el hemisferio derecho, mantiene un proceso paralelo, el cual busca pautas y no pasa de una característica a otra; es decir, contiene componentes y los organiza, el proceso surge debido a la percepción de los diferentes estímulos auditivos y visuales.

Entre las principales limitaciones del estudio, está la falta de información confiable aspecto que limitó el alcance del análisis, además, no existió gran variedad de estudios para citar en la investigación; sin embargo, la base de revisión de literatura, ayudó a sentar las bases para comprender el problema de investigación. Para futuras líneas de investigación, se sugiere con una investigación sistemática para cuestionar los supuestos de la neurociencia y la psicolingüística utilizando una amplia gama de medidas directas y objetivas del proceso de lenguaje.

\section{Referencias bibliográficas}

Ardila, A. (2015). Agnosias y apraxias. Neuropsicología, Neuropsiquiatría y Neurociencias, 15(1), 1-7.

Ardila, A. (2016). Área frontal derecha homóloga al área de broca: Participación en los procesos verbales. II Congreso Internacional de Neuropsicología en Internet. https://www.researchgate.net/ publication/289673976 A speech disorder associated with right Broca's homologous area pathology

Ardila, A., Bernal, B., y Rosselli, M. (2014a). Participation of the insula in language revisited: A meta-analytic connectivity study. Journal of Neurolinguistics, 29, 31-41. https://doi.org/10.1016/j. jneuroling.2014.02.001

Ardila, A., Bernal, B., y Rosselli, M. (2014b). The elusive role of the left temporal pole (BA38) in language: A preliminary meta-analytic connectivity study. International Journal of Brain Science, 2014, 946039. https://doi. org $/ 10.1155 / 2014 / 946039$

Ardila, A., Bernal, B., y Rosselli, M. (2016). Área cerebral del lenguaje: Una reconsideración funcional. Revista de Neurología, 62, 97-106. https://doi. org/10.33588/rn.6203.2015286

Blasco, E. (2006). Apraxia del habla: Presentación de un caso clínico. En B. Gallardo, C. Hernández y V. Moreno (Eds.), Lingüistica clínica $y$ neuropsicología cognitiva. Actas del I Congreso Nacional de Lingüística Clínica. Vol 1: Investigación e 
intervención en patologías del lenguaje (pp. 1-7). Universitat de Valéncia.

Bolaños, M. (2014). Niveles de ansiedad en estudiantes de psicología clínica $e$ industrial de la Universidad Rafael Landivar de tercer año de la jornada vespertina que están por iniciar las prácticas de intervención psicológica [Tesis de pregrado, Universidad Rafael Landivar]. http://biblio3.url. edu.gt/Tesario/2014/05/42/BolanosMaricarmen.pdf

Cabrales, A. (2015). Neuropsicología y la localización de las funciones cerebrales superiores en estudios de resonancia magnética funcional con tareas Neuropsychology and the localization of superior brain functions in fMRI with task studies. Acta Neurológica Colombiana, 31(1), 92-100. https:// doi.org/10.22379/2422402214

Coelho, F. A. (2017). Neurociencia: Un encuentro posible con la psicología humanística. Revista de Ciencias Sociales (Ve), XXIII(1), 58-66.

Cristiano, L. A. (2016). Aportes de la neurociencia a la enseñanza de léxico: Explorando la ruta cerebral del aprendizaje de palabras [Tesis de maestría, Pontificia Universidad Javeriana]. $\quad$ https://repository. javeriana.edu.co/handle/10554/19655

De la Barrera, M. L., y Donolo, D. (2009). Neurociencias y su importancia en contextos de aprendizaje. Revista Digital Universitaria, 10(4), 1-18. https://www.revista.unam.mx/vol.10/ num4/art20/art20.pdf

Esteban, S. (2014). Análisis lingüístico de muestras de habla de pacientes con afectación del lenguaje [Tesis de pregrado, Universidad de Valladolid]. https://uvadoc.uva.es/ handle/10324/7490
Estrada-Acuña, R. A., Arzuaga, M. A., y Giraldo, C. V. (2019). La teoría fundamentada clásica: Una opción para construir el camino investigativo durante la formación doctoral. Biblioteca LasCasas, $15 . \quad$ http:// ciberindex.com/index.php/lc/article/ view/e12345

Fernández, J. (2007). Lenguaje, cuerpo y mente: Claves de la psicolingüística. Per Abbat, (3), 39-71.

Flores, V., y Yánez, R. (2015). Influencia de la atención sostenida en la lectura comprensiva en los niños y niñas de 8 años de edad del Centro de Educación General Básica "La Providencia" en la Ciudad de Ambato. Revista Científica y Tecnológica UPSE, 2(2). https://doi. org/10.26423/rctu.v2i2.40

Geyer, S., Weiss, M., Reimann, K., Lohmann, G., y Turner, R. (2011). Microstructural parcellation of the human cerebral cortex - from Bbrodmann's post-mortem map to in vivo mapping with high-field magnetic resonance imaging. Frontiers in Human Neuroscience, 1-7. https://doi. org/10.3389/fnhum.2011.00019

Gómez, J. (Ed.) (2004). Neurociencia cognitiva y educación. Fondo Editorial FACHSE.

Gutiérrez, R. (2014). Interacción de los componentes del lenguaje oral en el proceso de aprendizaje de la lengua escrita [Tesis doctoral, Universitat D'Alacant]. http://rua.ua.es/dspace/ bitstream/10045/39868/1/tesis gutierrez fresneda.pdf

Hernández, R., Fernández, C., y Baptista, M. D. P. (2014). Metodología de la investigación. McGrawHill/ Interamericana Editores.

Luppino, G., Matelli, M., Camarda, R. M., Gallese, V., y Rizzolatti, G. (1991). Multiple representations of body 
Procesamiento cerebral del lenguaje desde la perspectiva de la neurociencia y la psicolingüistica

movements in mesial area 6 and the adjacent cingulate cortex: An intracortical microstimulation study in the macaque monkey. Journal of Comparative Neurology, 311(4), 463-482. $\quad$ https://doi.org/10.1002/ cne. 903110403

Marín, G. E. (2007). Estado del arte de la psicolingüística en Colombia. Cuadernos de Lingueistica Hispanica, (9), 109-120.

Nowinski, W. L., y Belov, D. (2003). The Cerefy Neuroradiology Atlas: A Talairach-Tournoux atlas-based tool for analysis of neuroimages available over the Internet. NeuroImage, 20(1), 50-57. https://doi.org/10.1016/S1053$\underline{8119(03) 00252-0}$

Paredes, J., y Varo, C. (2006). Lenguaje y cerebro: Conexiones entre neurolingüística y psicolingüística. En B. Gallardo, C. Hernández y V. Moreno (Eds.), Lingüistica clínica y neuropsicología cognitiva. Actas del I Congreso Nacional de Lingüística Clínica. Vol 1: Investigación e intervención en patologías del lenguaje (pp. 107-119). Universitat de Valéncia.

Rosselli, M., Ardila, A., y Bernal, B. (2015). Modelo de conectividad de la circunvolución angular en el lenguaje: Metaanálisis de neuroimágenes funcionales. Revista de Neurologia, 60, 495-503. https://doi.org/10.33588/ $\underline{\text { rn.6011.2015039 }}$

Sepúlveda, L., y Gaintza, Z. (2013). Perspectivas inherentes al desarrollo del lenguaje: Aportaciones desde la psicolingüística. Revista de Pedagogía Crítica Paulo Freire, (13), 65-83. https://doi. org/10.25074/07195532.13.411

Terranova, A. E., Viteri, E. A., Medina, G. M., y Zoller, M. J. (2019). Desarrollo cognitivo y funcionalidad familiar de infantes en las comunidades urbanomarginales de Ecuador. Revista de Ciencias Sociales (Ve), XXV(E-1), 330-340. https://doi.org/10.31876/rcs. $\underline{\mathrm{v} 25 \mathrm{i} 1.29626}$

Turkeltaub, P. E., Eden, G. F., Jones, K. M., y Zeffiro, T. A. (2002). Meta-analysis of the functional neuroanatomy of singleword reading: Method and validation. Neurolmage, 16(3), 765-780. https:// doi.org/10.1006/nimg.2002.1131

Vaca, M. J. (2013). Aplicación de terapia fonética y fonológica para la estimulación de áreas de Broca y Wernicke, en niños de 2 a 4 años de edad con trastorno expresivo del lenguaje que asisten al Centro Terapéutico Voces de enero a octubre de 2010 [Tesis de maestría, Universidad Central del Ecuador]. http://www.dspace.uce. edu.ec/bitstream/25000/2628/1/TUCE-0007-27.pdf

Valencia, Á. M. (2015). Eficacia de la musicoterapia en la recuperación de la articulación del lenguaje en un paciente diagnosticado con afasia de Broca: Estudio de caso en el Hogar Geriátrico "Plenitud Ciudad de la Alegría. [Tesis de pregrado, Universidad Central del Ecuador]. http://www.dspace.uce.edu.ec/ bitstream/25000/7148/1/T-UCE-0007281c.pdf

Yepes, D. (2013). Una aproximación a la lectura:Laperspectivapsicolingüística [Tesis de maestría, Universidad de Almería]. http://repositorio.ual.es/ bitstream/handle/10835/2310/Trabajo. pdf? sequence $=1 \&$ isAllowed $=y$ 